\title{
Potências do tempo na ficção científica em quadrinhos: pós-futurismo, antifuturismo e retrofuturismo
}

\author{
Potentials of Time in Science Fiction Comics: \\ Post-Futurism, Anti-Futurism and Retrofuturism
}

\author{
Alexandre Linck Vargas ${ }^{1}$
}

\author{
DOI: 10.19177/memorare.v8e12021217-228
}

\begin{abstract}
Resumo: 0 tempo da ficção científica não é o tempo crônico. Sua poética parece exigir um outro tempo, aiônico, estilhaçando o presente a partir de imagens do passado e do futuro técnico. Contudo, como é possível ainda existir ficção científica quando a perspectiva de futuro acaba? É a partir dessa questão que se investigará a produção de ficção científica em quadrinhos europeia pós-1977, marcada, na Itália, na França e no Reino Unido, por diferentes relações com o futuro. A história em quadrinhos franco-belga, com artistas como Yves Chaland, adota o retrofuturismo, resgatando o neofuturismo belga dos anos 1950. A italiana revista Cannibale, criada por Stefano Tamburini, traduz a estética antifuturista do Movimento de 77. E a criação da revista britânica 2000 AD, editada por Pat Mills, faz da narrativa distópica a imagem do pós-futuro. Tratase de uma pesquisa exploratória nos marcos da estética e cultura, utilizando-se de referencial bibliográfico e documental em quadrinhos.

Palavras-chave: Ficção científica; História em quadrinhos; Tempo; Futurismo; fim do futuro.
\end{abstract}

\begin{abstract}
The time of science fiction is not chronic. Its poetics seems to demand another time, aionic, shattering the present from images of the past and the technical future. However, how is it possible for science fiction to still exist when the future perspective is over? We'll start from this question to investigate the production of post-1977 European science fiction in comics, marked, in Italy, France and the UK, by different relations to the future. FrenchBelgian comics, with artists such as Yves Chaland, adopts retrofuturism, rescuing the Belgian neofuturism of the 1950s. The Italian magazine Cannibale, created by Stefano Tamburini, translates the anti-futurist aesthetics of the '77 Movement. Finally, the creation of the British magazine 2000 AD, edited by Pat Mills, makes the dystopian narrative the image of the post-future. This is an exploratory research in the framework of aesthetics and culture, using bibliographical and documental references on comics.

Keywords: Science fiction; Comics; Time; Futurism; End of the future.
\end{abstract}

\footnotetext{
1 Doutor em Literatura pela Universidade Federal de Santa Catarina. Professor em tempo integral da Universidade do Sul de Santa Catarina/Instituto Ânima; E-mail: linck.alexandre@gmail.com.
} 


\section{Introdução}

\section{Potências do tempo}

Uma constante atravessa toda produção de ficção científica (FC) de maneira mais ou menos ostensiva a depender da obra. Trata-se da complexidade dos tempos. Suvin (apud ROBERTS, 2018) já havia notado isso ao apontar o "novum" da FC. Através da relação entre o Velho e o Novo, a FC agencia de maneira bastante complexa duas instâncias de tempo. 0 Novo revela-se à superfície, quando o avanço técnico faz o papel de distinção e distanciamento do mundo em que vivemos. Ao mesmo tempo, o Velho retorna, como que no subsolo de toda FC, dando as bases imaginárias e nutrindo as mesmas novas tecnologias que nada mais são que extrapolações do passado.

Em outras palavras, poder-se-ia dizer que a FC é o amanhã que sonhamos ontem. Daí a decorrência de genealogias da FC que a situam a partir de um intervalo, fissura nunca resoluta entre magia-tecnologia, emoção-razão, luz-trevas etc. Para Roberts (2018), as condições de possibilidade da FC estão no confronto do protestantismo racional com o catolicismo mágico. Enquanto trauma coletivo de fissura na experiência religiosa europeia, a FC teria surgido como uma narrativa sintomática dessa dura desarticulação. Deste modo, a FC poderia de um lado evocar a razão pós-copernicana em seus aparatos técnicocientíficos e ainda assim cobri-los de uma aura de assombro mágicodivino.

Essa mesma tensão se desdobraria no duelo entre a razão esclarecida do Iluminismo e o sublime misterioso do Romantismo. Assim seria possível para a FC reunir de maneira orgânica, ainda que sempre conflituosa, a ciência, mesmo absurda, e o terror/fascínio que ela ocasiona. Esse conflito, porém, não é destrutivo à FC. Pelo contrário, é o núcleo pulsante de toda FC, é o que força a narrativa acontecer e dálhe ânimo. Enquanto resposta a uma razão desmaravilhada, a FC tornase, portanto, a sutura narrativa que outras frentes filosóficas, políticas e artísticas não conseguiram produzir.

A complexidade temporal é um tópico de suma importância. Pois na FC o passado e o futuro convivem, ou melhor, fatiam o presente. Deleuze (2009) ao explicar o tempo aiônico e sua diferença perante o tempo crônico, aprofunda o fenômeno da fragmentação do presente. Enquanto o tempo crônico é marcado por uma sucessão infinita de instantes, fazendo imperar um eterno presente circular, o tempo aiônico é fissurado pelo passado e pelo futuro a todo momento, e as virtualidades, outrora existências mínimas, atualizam-se em devires. Em outras palavras, se no tempo crônico a percepção do tempo é de uma narrativa orgânica da vida, demarcável pelas horas do relógio e consideravelmente previsível em seus acontecimentos, no tempo aiônico, eventos do passado irrompem na memória, traduzidos em ação, e povoam o presente. Isso por consequência torna o presente inoperante, sendo agora tumultuado pelas emergências do passado.

Nesse mesmo movimento, o futuro também se abre, multiplicandose às subjetividades desabrigadas desse presente que já não é mais capaz de organizar os eventos. Cabe contudo o alerta para não se fazer 
uma leitura crônica do próprio tempo aiônico. Pois o passado emergente e o futuro aberto não são dados em uma sequência, mas em simultaneidade. Ou seja, o futuro é o agente mobilizador do passado e vice-versa. É por que existe a perspectiva de um futuro que o passado vem à tona e vice-versa. Daí a compreensão que no tempo aiônico os virtuais são atualizados e os devires, isto é, pontos de fuga ontológicos, ganham vez: devir-animal, devir-mulher, devir-máquina do homem liberto de um presente orgânico.

O tempo aiônico não é exclusivamente um tempo da ficção. Ele pode ser encontrado na experiência da revolta, quando a vida miúda traduzida em uma rotina orgânica colapsa mediante as virtualidades explosivas do passado e do futuro. Jesi (2018) dirá que a revolta é um apelo, não ao amanhã, mas ao dia depois de amanhã. Pode-se dizer que esse dia é também o de antes de ontem, isto é, é o dia convergente futuro-passado/passado-futuro de um presente fraturado. É precisamente desta sensação que a FC recolhe sua poética do tempo.

A ciência não é tão somente um fundo tecnicizante da narrativa, mas seu tecido poético, que traz ou instiga o tempo de uma emergência, uma atualização do imaginário técnico de um presente criativamente fraturado. 0 paradigma desse acontecimento é Frankenstein, de Mary Shelley. Toda genealogia da FC que retorna à tragédia do cientista e seu monstro inevitavelmente acabará obrigada a reconhecer a anacronia como um elemento constitutivo. Pois, em Frankenstein, o passado mágico e o futuro científico convergem quando retratam a carne cadavérica do presente aos pedaços sendo precariamente costurada e animada. 0 monstro de Frankenstein é o corpo vivo das fatias de tempos divergentes, fragmentos do passado morto tecnicamente mobilizado em um futuro desconhecido.

Contudo, e se a técnica deixa de ser um agente catalizador de futuro?

Essa não é uma pergunta banal. Pois o que se observa com a falência do projeto moderno, naquilo que diferentes autores chamarão de pós-modernidade (LYOTARD, 2013), é a incapacidade da técnica enquanto vetor de um futuro. A modernidade deu à técnica a certeza de um dirigismo do tempo futuro. Seria a técnica a agenciadora do futuro, ou mais radicalmente, a técnica é a ação do humano que, separado da natureza atemporal, funda seu futuro historial (HEIDEGGER, 2007). Trata-se de um pensamento tributário às mudanças traumáticas e sublimadas por ocasião da revolução industrial.

A máquina ocuparia, assim, o lugar do Sublime burkeano (2013). Objeto informe e fonte de terror e fascínio, a máquina se distingue do Belo na medida em que não pode ser contemplada à uma distância segura, como um automóvel que vem em nossa direção. A máquina é móvel, ou mobilizante, e por isso qualquer esforço de estagnação para melhor retratá-la ou compreendê-la implicará em sua desativação, o que se torna dar um passo atrás na experiência mesma da máquina que intriga o humano. Afinal, uma vez desligada, a máquina não é mais o que era, e sua verdade não está mais ali.

Do mesmo modo, a forma da máquina jamais pode ser apreendida por completo, já que ela guarda segredos para além do humano, podendo ser gigantesca ou microscópica, e todo seu saber se recolhe sob

Memorare, Tubarão, v. 8, n. 1, jan./jun. 2021. ISSN: 2358-0593 
o signo do indescritível ou indecifrável, de relógios suíços a aceleradores de partículas. A vanguarda futurista foi o movimento artístico-filosófico que melhor traduziu não só o ânimo por um futuro maquínico, mas a crença na própria concepção sem reservas de futuro pela técnica. Isso conduziria ao elogio da violência do Novo, clamando por museus e bibliotecas incineradas e pela beleza das máquinas de guerra, como faria Marinetti (2009) no Manifesto Futurista.

Porém, a experiência pós-guerra produziu um ponto de inflexão. De Auschwitz à Hiroshima, a técnica mostrou-se não mais capaz de afiançar o futuro, mas de sistematicamente exterminá-lo. Dois momentos seriam decisivos para esse mal-estar no pensamento contemporâneo no século XX. 0 primeiro em 1968, quando essa tensão explode e o futuro é agressiva e festivamente convocado para que potências paratécnicas sejam capazes de reinventar a vida, ora pela panfletagem impressa, pelas técnicas de confronto e conciliação, pela guitarra elétrica, pelas drogas sintéticas ou pela errância em automóveis e motocicletas.

A técnica é então posta não mais na condição econômica de ganho, isto é, de saber que traz vantagem para seu detentor, um paradigma em voga desde a ascensão da burguesia. 0 que se conclama é pelo valor de despesa da técnica, seu emprego inútil, desfrutável, inoperante, saber desvantajoso e, por isso, comunitário (BATAILLE, 2013). Contudo, a promessa de 1968 não se concretiza e em 1977 uma segunda onda ganha corpo. Desta vez, não se trata mais de fazer exigências do futuro, mas de sumariamente negá-lo. 0 futuro torna-se, então, para a sensibilidade neodadaísta da estética punk um não-tempo, conforme o refrão "no future" em God Save the Queen da banda Sex Pistols; a economia sob o paradigma neoliberal autoproclama-se o fim da história (BERARDI, 2019); e a cultura pop prolifera imagens do fim dos tempos, seja japonesa a partir do cyberpunk de Akira e sua grande repercussão no ocidente, seja estadunidense, com Watchmen nos quadrinhos, O Dia Seguinte na televisão, Blade Runner nos cinemas, entre outras.

O ano de 1977 é o ano da guinada na história da modernidade, o ano em que toma forma a perspectiva pós-humana. Nesse ano, mudam de perspectiva e de significado todos os rituais coletivos: a política, a espiritualidade e a música adquirem um sentido apocalíptico que não encontra uma linguagem adequada para se expressar. 0 momento da última revolta contra a desumanização é também aquele em que a mutação começa a ocorrer. A geração que vem ao mundo nos anos 1980 está destinada a ser a primeira geração videoeletrônica, a primeira que se forma em um ambiente em que a mídia prevalece sobre o contato com o corpo humano. Nos anos culturais e estéticos, assistimos a um processo de depuração, de descarnalização. (...) 0 organismo é sensibilizado ao código e, assim, predisposto à conexão, à interface permanente com o universo digital. Em 1977, houve a repentina tomada de consciência do fato de que a história é história de automatismos irreversíveis. (BERARDI, 2019, p. 87-88)

A técnica passa a se confundir com a própria vida. Não há mais governança humana que possa fazer dela útil ou inútil. A técnica é agora interior ao humano, faz parte da programação cibergenética de seu espaço-tempo - para usar um vocabulário kantiano, é sua condição de possibilidade. Os sujeitos, portanto, só existem porque os dispositivos técnicos assim o permitem. 
Cabe ressalvar que essa mudança é menos material e mais epistêmica. Afinal, o que ocorre na virada do século XX para o XXI é apenas a radicalização de um processo e sua consciência crítica em perspectiva. Por isso Foucault fará uso do conceito do dispositivo como produtor de sujeitos para pensar inclusive a linguagem (AGAMBEN, 2005), Deleuze e Guattari (2011) irão opor ao inconsciente pulsional freudiano o conceito de inconsciente maquínico, e Peter Sloterdijk (1999) fará uma genealogia da antropotecnia genética no período paleolítico.

Nesse cenário, cabe questionar em que território situa-se a FC. Como uma poética criada pela repartição múltipla do presente pelo passado e futuro procede quando o futuro torna-se inexistente? A resposta não é única, mas encontra-se nas diferentes maneiras que o tempo futuro, ou antes, a impossibilidade do futuro, fratura o presente. Dito na forma de um pequeno chiste, a FC sobrevive na contemporaneidade por meio de condições de impossibilidade.

Serão analisadas aqui três histórias em quadrinhos (HQs) europeias de FC, todas pós-1977 e de natureza poética bastante distintas. Optou-se pelo recorte de quadrinhos europeus devido à concepção de fim do futuro ter sua ancoragem na experiência europeia e ganhar nas produções locais contornos mais expressos de um mal-estar, ainda que a mesma sensação pareceu reverberar em grande parte da produção cultural mundial. Busca-se com as análises que seguem, portanto, elucidar o tempo complexo da FC contemporânea e, em um mesmo gesto, fazer um comentário sobre a concepção de futuro na atualidade.

\section{Pós-futurismo: Juiz Dredd}

Em 1977, no Reino Unido, seria lançada o semanário em quadrinhos de ficção científica $2000 A D$, publicada pela IPC Magazines e editada por Pat Mills, responsável pelas revistas Battle Picture Weekly (1975-1988) e Action (1976-1977). Enquanto a primeira foi uma revista em quadrinhos de guerra e durou por mais de uma década, a segunda teve uma vida relâmpago e ganhou status de cult por causa de sua abordagem e da polêmica que atraiu.

Action era uma revista popular de HQs com violência gráfica e conteúdo político de esquerda que reciclava conceitos de sucesso do cinema, literatura ou quadrinhos. Acabou por repercutir na imprensa com matérias sobre seu conteúdo no Evening Standard, The Sun e BBC. Uma campanha por sua censura ou banimento foi liderada por Mary Whitehouse, do grupo conservador de vigilância moral de impressos National Viewers' and Listeners' Association. Pressões externas e internas acabaram forçando o cancelamento da Action que conseguiu sobreviver metamorfoseando-se na $2000 \mathrm{AD}$. A guinada à $\mathrm{FC}$ foi providencial, pois permitiu que o conteúdo político fosse mais alegórico, ainda que a violência gráfica se mantivesse em alguma dose (MILLS, 2017).

Foi no segundo número da $2000 \mathrm{AD}$ que estreou aquele que seria o personagem mais famoso da revista e, hoje, dos quadrinhos britânicos. Juiz Dredd, criado por John Wagner e Carlos Ezquerra, e com contribuição direta de Pat Mills, foi narrativa e graficamente uma 
subversão de diferentes gêneros sob o teto da FC. A história passa-se no ano de 2099. Após um conflito nuclear em 2070, o mundo foi reduzido a poucas megalópoles, cidades-estados, governadas por Juízes. 0 sistema de Juízes é de natureza jurídica complexa. 0 Juiz é ao mesmo tempo policial, juiz e, como idealizara Pat Mills, executor.

Trata-se, portanto, de uma figura de suma autoridade, capaz de atalhar o processo jurídico em uma cidade hiperpopulosa. É o caso de Mega-City One, uma gigantesca cidade-estado que se estende por toda a costa leste dos EUA habitada por 800 milhões de pessoas. 0 Juiz mais temido de Mega-City One é Dredd, homem incorruptível e austero, geneticamente projetado, e que nunca será visto sem seu capacete e visor.

À primeira vista, Juiz Dredd é somente a história de um Dirty Harry futurista em uma distopia fascista. Contudo, a HQ vai ganhando personalidade no decorrer da série e o mundo de Dredd desdobrandose. Tropos de diferentes gêneros são evocados e cruzados.

Primeiramente, Juiz Dredd é um policial hardboiled, buscando justiça em um mundo sujo, corrupto e criminoso. Contudo, diferentemente desse subgênero policial, as instituições (o sistema dos Juízes) não é falha, e Dredd jamais se desvia da lei para cumprir seus objetivos. Esse bommocismo e visão positiva do poder vigente decorre de outro gênero, no caso, os quadrinhos estadunidenses de super-heróis, que em sua roupagem clássica apresentava figuras íntegras a serviço de um regime que pode sofrer dificuldades (e demandar o vigilantismo), mas não é estruturalmente problemático.

Os quadrinhos de Dredd também flertam com o western, quando o aproximam à figura de um xerife que busca fazer imperar a lei em mundo à beira do caos. Por fim, a sátira. Juiz Dredd é por vezes interpretado como um elogio ao autoritarismo heroico (como na adaptação cinematográfica estadunidense de 1995), quando, muito expressamente o que as HQs fazem é, pela hipérbole, debochar e disparar críticas à política do agora. A violência gráfica em preto e branco, com leiautes pesados e desenhos sujos, corroboram essa sensibilidade punk de contestação pela ironia.

Tudo isso é envelopado pela FC, que aqui especificamente serve para produzir a percepção de um pós-futuro. Afinal, o futuro é um tempo inexistente em Juiz Dredd. De maneira extradiegética pela ironia narrativo-gráfica que a todo momento nos devolve ao presente. 0 futuro como território lúdico é uma instância insistentemente negada. Contudo, é pela intradiegese que o futuro é mais intensamente impossibilitado - ou antes, superado. Pois o que Juiz Dredd nos mostra é um estado de coisas relativamente estabelecidas, em um mundo no qual o futuro já veio, trouxe guerra, dor e morte, e dele restou o continuum fascista do presente.

Daí o pós-futurismo de Juiz Dredd, a condição de que o tempo que vivemos é aquele em que o futuro já é passado. Em outras palavras, o presente e o futuro permutam ironia e distopia (presente irônico do futuro distópico, futuro irônico do presente distópico), e assim o fazem delegando a um passado histórico (ficcional ou não) o único horizonte de mudanças já superado, ainda que recorrente, atualizável na vida em seu eterno fracasso. 


\section{Antifuturismo: Ranxerox}

Uma perspectiva diferente de futuro emergirá da produção quadrinística italiana. Decisivo para essa sensibilidade será o Movimento de 77. Esse levante social e contracultural, majoritariamente estudantil, romperá com as demandas de 68, insurgindo-se contra o Compromesso storico entre a Democracia Cristã e o Partido Comunista Italiano. Ocorrem ocupações das universidades de Palermo, Milão e Roma. Contudo, o acontecimento determinante foi em Bologna em 11 de março de 1977, com a morte de Franceso Lo Russo enquanto fugia da polícia, o que tornou a cidade o epicentro dos protestos. Bologna era "o lado criativo do Movimento" (CASTALDI, 2010).

A cena era composta pelo coletivo "maodadaista" A/traverso, a rádio Alice, uma das primeiras rádios livres, inspirada na análise de Deleuze em Lógica do Sentido, e uma crescente produção musical independente. Os quadrinhos também eram parte importante. Foi na Bologna de 1977 que surgiu a revista Cannibale (1977-1979), criada por Stefano Tamburini, em referência à homônima revista dadaísta de Francis Picabia, de 1920. Nela estrearia, em seu terceiro número, Ranxerox, de Tamburini (VARGAS; MARCONDES, 2019).

Ranxerox é um Frankenstein punk pós-moderno. Sua mítica criação se deu quando Tamburini viu um grupo de estudantes chutando uma fotocopiadora. 0 quadrinho se passa em futuro distópico próximo, a Roma de 1988, estruturada em dezenas de níveis pelos quais os estratos sociais são separados. Ranxerox é um androide construído por "estudenliquentes" a partir de uma máquina xerox roubada. Diferentemente do monstro de Mary Shelley, Ranxerox é criado por razões fortuitas: drogar-se, comer, beber, transar, e eventualmente fazer alguns serviços para o seu criador, que é perseguido político.

Durante um reparo, no qual seu potenciômetro de agressividade estava disparado, a polícia encontra os estudenliquentes, que são prontamente assassinados, cabendo a Ranxerox revidar na mesma proporção. "Tamburini tem fascínio pela questão da cópia. Duas de suas criações, Snake Agent e Yorga, são simplesmente cópias distorcidas e remontadas de antigas HQs norte-americanas com textos alucinados inseridos à maneira do détournement situacionista" (CAMPOS, 2010, p. 8).

Ranxerox é uma máquina não produtiva em um tempo futuro sem futuro. A ironia é ele ser construído a partir de uma fotocopiadora, uma aparelho de reprodutibilidade técnica. Ou seja, Ranxerox reproduz o humano, contudo, não o humano ideologicamente construído a partir do discurso utilitarista, mas o sujeito não empregado pelas forças dominantes, uma espécie de proto-eu ainda e em constante estado de exuberância improdutiva.

Porém, diferentemente do monstro de Frankenstein que, por vezes, assemelha-se a uma desajeitada criança ao brincar, e para sempre deslocado socialmente, Ranxerox vai aos poucos personificando a apatia adulta, arranjando subempregos e sustentando os caprichos da esposa Lubna, uma menina de 12 anos. Porém, permanece subjetivamente resistente a qualquer investimento discursivo de uma sociedade na qual 
o progresso técnico é a saída, sendo essa a grande ironia, pois ele, enquanto uma máquina avançada, é, a rigor, o corpo desse discurso.

Esteticamente a série reflete essa evolução de Ranxerox. Quando na Cannibale, a narrativa gráfica é dramática, a ação é brutal, com paisagens reticuladas e claustrofóbicas em preto e branco. Depois, quando a série passa a sair na revista Frigidaire, de 1980, também fundada por Liberatore, a série ganha a arte hiper-realista de Tanino Liberatore, que traz consideráveis mudanças: as cores são desbotadas, a ausência de sombras duras produz assepsia, a apatia torna-se um efeito não só narrativo como gráfico em grandes cenas urbanas industriais, e a dramatização dá lugar ao humor negro e o cinismo.

Costuma-se apontar certa despolitização das histórias conforme afastavam-se do movimento de 77, porém, o que se percebe é uma radicalização do mal-estar original. 0 que Ranxerox cristaliza é a sensação de impossibilidade do futuro, desfuncionalidade do próprio tempo. Tudo na série tende a uma reprodução sem fim, um circuito fechado, no qual o presente impera perante um antifuturo.

Da revolução jamais concretizada à medíocre rotina moderna, mesmo em seu íntimo, Ranxerox está preso a um eterno retorno. Ele que fora uma fotocopiadora senciente, programada para a sobrevivência, o ódio e a indiferença, tem no amor dócil por Lubna uma falha no sistema. Porém, essa mesma falha que se torna sua força motriz, o levará fatalmente a ser uma máquina estúpida e inútil mais uma vez.

$\mathrm{O}$ antifuturo da FC de Ranxerox opera, portanto, negando qualquer futuro e, ao mesmo tempo, estendendo o presente. Esse mesmo presente torna-se o longo futuro - e por consequência, o longo passado também, pois a vida miúda do agora não tem qualquer traço de historicidade e a máquina que a reproduz não guarda memória. Ainda assim, não é o retorno do tempo crônico, e, sim seu dispositivo posto em condições aiônicas.

Dito de outro modo, em Ranxerox o presente imperativo do tempo crônico é exposto ao máximo como o lugar onde o futuro e o passado se insistem, mas são rechaçados. Trata-se de evidenciar não a inexistência do tempo aiônico, fundamental para qualquer FC, mas por ele acusar um tempo crônico que repele a todo instante, como uma fotocopiadora do "agora", qualquer possibilidade de fratura do tempo.

\section{Retrofuturismo: Freddy Lombard}

Foi em 1977 que o quadrinista holandês Joost Swarte cunhou o conceito de "estilo atômico" (atoomstijl) ao futurismo belga dos anos 1950 nas histórias em quadrinhos. Existem duas escolas estilísticas de forte tradição na Bélgica. A primeira, a escola de Bruxelas, seria personificada em Tintim (1929) e seu criador Hergé. Swarte, um pouco antes em 1977, a batizaria de "linha clara". Suas principais características seriam os traços de espessura e valor uniforme, os elementos demarcados, a ausência de efeitos de luz e sombra, as cores primárias sem saturação, os personagens cartunescos em cenários realistas e o leiaute regular.

Contudo, seria em Marcinelle que surgiria uma segunda escola, desta vez simbolizada por Spirou (1938), criado por Rob-Vel e sucedido por Jijé e André Franquin em seus primeiros anos. Diferentemente dos 
quadrinhos de Tintim que eram mais ilustrativos em suas composições e a ação elipsada, Spirou utilizava-se de uma decupagem mais cinematográfica, o traço cartunesco era mais solto e selvagem, as cores mais vivas, os efeitos de luz e sombra eram dramáticos e o leiaute mais dinâmico. Contudo, foi no pós-guerra que a estilística de Marcinelle encontraria um motivo para além da típica narrativa de aventura comum às duas escolas. Trata-se, portanto, do nascimento do "estilo atômico".

É possível traduzir o "estilo atômico" como um neofuturismo belga, pois refere-se sobretudo a uma resposta otimista perante o futuro após a experiência traumática de sofrimento e austeridade durante a Segunda Guerra Mundial. Jijé, André Franquin, Will, e depois Jidehem e Maurice Tillieux, repercutiriam esses anseios, entendidos como um apelo à modernidade, uma grande receptividade dos avanços artísticos e tecnológicos, assim como uma maior assimilação do "American dream".

Deste modo, Spirou e Fantasio, seu parceiro criado durante a guerra, passarão a usar aparelhos tecnológicos e carros sofisticados; Monsieur Choc (1953), de Rosy e Will, e Modeste et Pompon (1955), de Franquin (desta vez pelo Le Journal de Tintin) exibirão elegantes designs de interiores; e temas como rock'n'roll, corrida espacial e energia atômica serão recorrentes. É de 1958 o Atomium, "a torre Eiffel de Bruxelas", pela ocasião da Expo 58, a primeira grande Exposição Mundial depois da Segunda Guerra Mundial.

Apesar do discurso futurista, ou antes, por causa dele, a exibição trazia o que havia de mais avançado em consonância com a ostentação do poder colonial belga, havendo inclusive um zoológico humano de congolenses e um apelo à "evolução", utilizando-se de um busto do Rei Leopoldo II, notório genocida do Congo, com milhões de vítimas estimadas. Contudo, foi o imaginário lúdico do futurismo pós-guerra que foi resgatado nos anos 1980 a partir do conceito de "estilo atômico".

Decisivo para isso foi o encontro em 1980 entre três jovens artistas parisienses, Yves Chaland, Serge Clerc e Luc Cornillon, e os gêmeos Daniel e Didier Pasamonik, editores da Magic Strip, especializada na reimpressão de quadrinhos belgas clássicos. Dali surgiu a coleção Atomium 58, uma série de quadrinhos publicados em formato álbum nos quais a tônica era a nostalgia, resgatando as linhas dinâmicas, o culto à máquina e os designs arrojados dos anos 1950. Essa coleção de álbuns pequenos $(16,5 \times 24,5 \mathrm{~cm})$ e impressão duotônica se tornaria o principal catálogo do "estilo atômico", duraria por toda a década de 80 e seria formada no total por 27 álbuns.

Não é por acaso que a inciativa foi encabeçada por franceses, e não necessariamente belgas. Os quadrinhos franceses vinham em um crescente realismo (LECIGNE; TAMINE, 2014), e a resistência a essa guinada deu-se em um retorno aos fundamentos do cartunesco da tradição belga. Contudo, o específico encanto pelo neofuturismo do pósguerra é digno de atenção. 0 que a experiência do Atomium 58 parece demonstrar é menos uma nostalgia ou uma disputa artística, e mais um mal-estar difícil de definir. Nesse sentido, Freddy Lombard (1981), de Yves Chaland, inicialmente publicado pela Atomium 58, acaba por ser um bom estudo de caso. 
Freddy Lombard é uma versão de Tintim. Traz o emblemático topete e sua principal característica é a disposição para a aventura. Contudo, as semelhanças param por aí. Lombard é ranzinza, espertalhão e aproveitador. Ele procura sempre ter vantagem nas relações, ainda que possua um senso moral. Daí seu otimismo, bastante distinto daquele de Tintim, pois sua crença não está exatamente na ideia de que as coisas vão melhorar, mas de que elas podem melhorar para ele. Suas aventuras, situadas nos anos 50, são menos um empreendimento ingênuo e romântico e mais uma inciativa oportunista ou um encontro fortuito em uma comédia de erros.

Lombard é acompanhado do forte e sedutor Sweep e da elegante e racional Dina. Permanece em eterno limiar se o trio de sagazes aventureiros são em sua essência golpistas de bom coração ou aventureiros que se utilizam de alguma malandragem pela manutenção do estilo de vida. Seja como for, torna-se um elemento novo as agruras econômicas e existenciais de um aventureiro, e não somente os desafios da aventura. Já seu grafismo reproduz inclusive os retratos estereotipados de pessoas africanas e de máquinas maravilhosas, como o super-avião F.52 que dá nome ao quinto e último álbum do personagem de 1989. Não há um discurso crítico sobre o resgate desse imaginário, mas, ao mesmo tempo, seu simples anacronismo faz dos heróis menos heroicos, mais frágeis em seu papel moral perante outros povos e em sua vida quando a mercê da máquina.

Por tudo isso, Freddy Lombard parece sintomatizar não um retorno romântico dos anos 50, mas um mal-estar que faz desse passado um lugar de resignação. Ele pode não ser considerado hoje uma FC, faltam muitos dos elementos comuns, ainda que evoque o que outrora era um horizonte de FC. É nesse sentido, porém, que está a FC, não enquanto gênero ou mesmo estrutura, mas como potência. 0 retrofuturismo de Freddy Lombard apela para todo um mundo a se especular, com cenários elegantes, tecnologias promissoras e aventura porvir. Contudo, isso acontece no passado.

É como se toda possibilidade de futuro houvesse apenas no retorno ao passado, no momento em que nós ainda tínhamos algum futuro, fosse ele ingênuo ou problemático. Por isso o constante desconforto que segue no subsolo narrativo-gráfico e subverte toda a alegria inocente que Freddy Lombard poderia produzir. Deste modo, mais uma vez, um regime de tempo distinto insinua-se, pois não é o tempo crônico aquele que dá lugar ao retrofuturismo, mas o tempo aiônico que reconhece no presente o espaço de um estilhaçamento, nesse caso, capaz de fazer o futuro gravitar no próprio passado e, ao mesmo passo, lança-lo inexoravelmente a um futuro negativo.

\section{Conclusão}

Há uma ironia macabra ao considerar como esses três contrafuturismos chegaram ao fim. Stefano Tamburini morreu de overdose da mesma heroína que tanto povoava os quadrinhos de sua geração em abril de 1986. Yves Chaland foi vítima das máquinas engenhosas que ele tanto admirava, morrendo em um acidente de carro em 18 de julho de 1990. Já a 2000 AD, que com Juiz Dredd imaginava o futuro através dos EUA, viu boa parte de seus talentos rumarem suas 
carreiras na virada da década de 80/90 para a estadunidense DC Comics, no que veio a ser chamado de "invasão britânica", o que demandou uma reestruturação da revista. Poder-se-ia dizer, portanto, que o pós-futurismo, o antifuturismo e o retrofuturismo convergiram, afinal, ao presente unificador, estado de coisas do tempo crônico. Não por menos, a ficção científica perdeu sua força, ou mesmo sua instância de tempo possibilitadora nessas quadrinhografias.

Contudo, cabe reforçar que essa percepção é bastante eurocêntrica, assim como próprio fim do futuro em 1977 (BERARDI, 2019). Ou seja, o futuro chegou ao fim, assim como sua negação também se esgotou na década de 90 na Europa. Porém, seria no mínimo desleixado desconsiderar a ascensão do ciberpunk japonês com Akira ou Ghost in the Shell, da Space Opera estadunidense com Star Wars, assim como a produção de FC em países latino-americanos, agora distensionada conforme saíam da ditaduras militares. Se o neoliberalismo ascendente desde o final dos 70 é um fator estrutural e global, capaz de universalizar o fim do futuro de Berardi, esse futuro, salienta-se, é aquele que a Europa poderia oferecer. Existem outros, porém. Assim como o tempo da ficção científica quadrinizada continua sendo a potência contra todo o império do agora.

\section{Referências}

AGAMBEN, Giorgio. 0 que é um dispositivo? Outra Travessia, Florianópolis, n. 5, p.9-16, 2005.

BATAILLE, Georges. A parte maldita, precedida de "A noção de dispêndio". Belo Horizonte: Autêntica, 2013.

BERARDI, Franco. Depois do futuro. São Paulo: Ubu, 2019.

BURKE, Edmund. Uma investigação filosófica sobre a origem de nossas ideias no sublime e no belo. 2 ed. Campinas: Unicamp, 2013.

CAMPOS, Rogério de. Prefácio da edição brasileira. In: TAMBURINI, Stefano; LIBERATORE, Tanino; CHABAT, Alain. RanXerox. São Paulo: Conrad, 2010.

CASTALDI, Simone. Drawn and dangerous: Italian comics of the 1970s and 1980s. Jackson: University of Mississippi, 2010.

DELEUZE, Gilles. Lógica do sentido. São Paulo: Perspectiva, 2009.

DELEUZE, Gilles; GUATTARI, Félix. 0 anti-Édipo: capitalismo e esquizofrenia. São Paulo: $34,2011$.

GRAVETT, Paul. In Search of The Atom Style. 2009. Disponível em: http://www.paulgravett.com/articles/article/in_search_of_the_atom_style1/. Acesso em: 16 jun. 2021.

HEIDEGGER, Martin. A questão da técnica. Scientiae Studia, [S.L.], v. 5, n. 3, p. 375-398, set. 2007. FapUNIFESP (SciELO). http://dx.doi.org/10.1590/s1678-

JESI, Furio. Spartakus: simbologia da revolta. São Paulo: N-1, 2018.

LECIGNE, Bruno; TAMINE, Jean-Pierre. Modern realism. In: MILLER, Ann; BEATY, Bart

(Ed.). The French comics theory reader. Leuven: Leuvein University, 2014.

Memorare, Tubarão, v. 8, n. 1, jan./jun. 2021. ISSN: 2358-0593 
LYOTARD, Jean-François. A condição pós-moderna. 15 ed. Rio de Janeiro: José Olympio, 2013.

MARINETTI. O futurismo. In: TELLES, Gilberto Mendonça. Vanguarda européia e modernismo brasileiro: apresentação dos principais poemas metalinguísticos, manifestos, prefácios e conferências vanguardistas, de 1857 a 1972. Petrópolis: Vozes, 2009.

MILLS, Pat. 2000AD and Judge Dredd: the secret history. Málaga: Millsverse, 2017.

ROBERTS, Adam. A verdadeira história da ficção científica: do preconceito à conquista das massas. São Paulo: Seoman, 2018.

SLOTERDIJK, Peter. No mesmo barco: ensaio sobre a hiperpolítica. São Paulo: Estação Liberdade, 1999.

VARGAS, Alexandre Linck; MARCONDES, Ciro Inácio. Os quadrinhos italianos pós-77 e o povo porvir: Ranxerox e Squeak the Mouse. Memorare, Tubarão, v. 6, n. 2, p. 185, 20 dez. 2019. Universidade do Sul de Santa Catarina - UNISUL. http://dx.doi.org/10.19177/memorare.v6e22019185-202.

Artigo enviado em: 17/06/2021. Aprovado em:29/06/2021. 